\title{
Sobreposição no desenvolvimento bilíngue bimodal
}

\section{Code-blending in Bimodal Bilingual Development}

Ronice Müller de Quadros*

Universidade Federal de Santa Catarina

Florianópolis - Santa Catarina / Brasil

Diane Lillo-Martin**

University of Connecticut

Storrs - Connecticut / Estados Unidos

Deborah Chen Pichler***

Gallaudet University

Washington D.C / Estados Unidos

\begin{abstract}
RESUMO: Crianças bilíngues desenvolvem sensibilidade para escolher as línguas de seus interlocutores de forma muito precoce, o que se reflete nas proporções diferenciadas do uso de cada língua. Os fatores tais como o contexto do discurso e a relativa dominância das línguas na comunidade podem também determinar o grau de diferenciação dos usos das línguas nas crianças em fase préescolar. Crianças bilíngues bimodais, ou seja, as que estão adquirindo uma língua de sinais e uma língua falada, simultaneamente, estão diante de um contexto mais complexo de negociações. Além da alternância de línguas, essas crianças produzem a sobreposição de línguas, que é um fenômeno sociolinguístico análogo àquele, mas sem a supressão de uma das línguas. Este estudo analisa produções espontâneas de crianças bilíngues bimodais, interagindo com seus interlocutores surdos ou ouvintes (duas crianças americanas e duas brasileiras). Nossos resultados mostram que, mesmo nas produções mais iniciais, as crianças produzem mais enunciados sinalizados com seus interlocutores surdos e mais enunciados falados com os seus interlocutores ouvintes. Todas as quatro crianças produziram enunciados bimodais, tanto nas sessões em que a língua alvo era a fala ou os sinais, mas de forma muito mais frequente nas sessões em sinais, potencialmente porque as crianças acham mais difícil suprimir a língua dominante. Esses resultados indicam que essas crianças bilíngues bimodais são
\end{abstract}

*ronice.quadros@ufsc.br

** lillo.martin@uconn.edu

*** deborah.pichler@gallaudet.edu 
sensíveis às línguas e seus interlocutores, enquanto apresentam uma influência considerável da língua dominante da sua comunidade.

PALAVRAS-CHAVE: Bilinguismo bimodal, desenvolvimento bilíngue, sobreposição de línguas, alternância de línguas, sensibilidade ao interlocutor.

ABSTRACT: Bilingual children develop sensitivity to the language choice of their interlocutors at an early age, reflected in differential proportions of the use of each language. Factors such as discourse context and relative language dominance in the community may also mediate the degree of language differentiation in preschool-age children. Bimodal bilingual children, those acquiring both a sign language and a spoken language, have an even more complex situation to negotiate. Besides the code-switching, the bimodal bilinguals engage in code-blending, a phenomenon with sociolinguistic uses that is analogous to code-switching, but without suppressing one of the languages. This study analyzes longitudinal spontaneous production data from four bimodal bilingual children (two Americans and two Brazilians). Our results show that even in the earliest observations, the children produced more signed utterances with their deaf interlocutors and more speech with their hearing interlocutors. All four children had used bimodal production in sign and speech sections, potentially because they find the suppression of the dominant language more difficult. The results reported here indicate that these preschool bimodal bilingual children are sensitive to the language status of their interlocutors, while showing a considerable influence from the dominant community language.

KEYWORDS: Bimodal bilingualism, bilingual development, language codeblending, language code-switching, interloctor sensitivity.

\section{INTRODUÇÃO}

Tem havido muito interesse em compreender como acontece o desenvolvimento das línguas em crianças bilíngues nativas, especialmente quanto à interação e separação das línguas. Tem sido observado que, principalmente nos estágios bem iniciais de aquisição, as crianças parecem misturar suas línguas, usando estruturas que aparentemente combinam elementos de ambas as línguas (GROSJEAN, 1989; BHATIA \& RITCHIE 1999; PARADIS, 2001). Além disso, as crianças interagem com falantes de uma de suas línguas (vamos dizer, a língua A) usando elementos de sua outra língua (a língua) - apresentando evidências de que ainda não separa as línguas no discurso (PARADIS \& NICOLADIS, 2007). Isso levou a uma proposta de que as línguas das crianças bilíngues estariam apresentando um tipo de "fusão" de línguas nos primeiros estágios de aquisição (VOLTERRA \& TAESCHNER, 1978), isto é, elas teriam uma gramática com elementos de ambas as línguas. 
No entanto, muitos autores têm se posicionado contra esta proposta de "fusão" de línguas (GENESEE, 1989). Eles apontam, por exemplo, que mesmo adultos bilíngues muito fluentes nas duas línguas podem produzir estruturas "misturadas" apresentando elementos das duas línguas. Os bilíngues adultos que são fluentes nas duas línguas permitem que as línguas interajam em diferentes contextos e de formas bastante interessantes (COSTA \& SANTESTEBAN, 2004; BISHOP \& HICKS, 2005; GONZÁLEZVILABAZO \& LÓPEZ, 2012). A alternância de línguas (code-switching) é um sinal indicativo da proficiência bilíngue (POPLACK, 1980; LUCAS \& VALLI, 1992), muito usada enquanto fenômeno sociolinguístico em comunidades bilíngues (BHATT \& BOLONYAI, 2011). Portanto, não é possível afirmar que as línguas das crianças sejam completamente separadas (UNSWORTH, 2013). Concluímos, portanto, que o melhor caminho seja na direção do entendimento sobre o desenvolvimento do bilinguismo, tendo como referência o estado do adulto e verificando nas crianças as direções no sentido de alcançar este estado.

Nosso projeto tem a seguinte proposta: nós estamos desenvolvendo um modelo de bilinguismo que possa ser aplicado tanto para os estados dos adultos, como de crianças, mesmo que o conhecimento gramatical das crianças possa ser diferente dos do adulto. Nosso projeto avança no seguinte aspecto: nós estamos desenvolvendo um modelo para o bilinguismo bimodal: crianças que sejam bilíngues com uma língua de sinais e uma língua falada. A maioria das crianças que estamos estudando são ouvintes, mas com famílias com surdos (pelo menos um ou ambos os pais) que usam a língua de sinais. Essas crianças, portanto, estão adquirindo a língua de sinais em casa e a língua falada com outras pessoas da comunidade (incluindo outros parentes que sejam ouvintes). Diante disso, a questão que se apresenta está relacionada com a separação e mistura das línguas nos contextos de bilinguismo bimodal.

Os poucos estudos existentes sobre bilíngues bimodais apresentaram várias conclusões. A primeira é que, assim como com bilíngues unimodais, as duas línguas dos bilíngues bimodais estão ativas e influenciam os seus usos e processamento, mesmo em contextos que requerem apenas uma das línguas (KROLL \& STEWART, 1994; KROLL et al., 2006; EMMOREY et al., 2008; SHOOK \& MARIAN, 2012). Os vários tipos de mistura de línguas observados em bilíngues unimodais podem também ser identificados com bilíngues bimodais, mas com algumas diferenças. A alternância de línguas - a interrupção da produção de uma língua (por exemplo, da língua falada) e o início da produção da outra língua (por exemplo, da língua de sinais) - 
é relativamente rara. Emmorey et al. (2008) investigaram adultos bilíngues bimodais, chamados de "Codas" ('child of Deaf adult', criança filha de pais surdos, nestes casos, incluindo crianças e/ou adultos ouvintes), em contextos bilíngues bimodais (um adulto Coda conversando com outro adulto Coda). De modo geral, os participantes produziram somente 6,26\% de alternância de línguas dos enunciados analisados. Por outro lado, eles tiveram um outro tipo de "mistura" de línguas, exclusivo de bilíngues bimodais: a sobreposição de línguas. Essa sobreposição é um uso natural e espontâneo da fala e dos sinais produzidos simultaneamente. Nos dados coletados por Emmorey et al. (2008), $35,71 \%$ dos enunciados foram sobrepostos. Os autores também observaram o uso de estruturas da língua de sinais na língua falada - chamados de influência interlinguística, ou transferência - outro tipo de "mistura" de línguas.

Bilíngues bimodais introduzem um novo tipo de "mistura" para os estudos sobre a interação das línguas em bilíngues. Eles produzem estruturas com interferência interlinguística e alternância de línguas, bem como apresentam de forma produtiva a sobreposição de línguas. Qualquer modelo de bilinguismo tendo como alvo a criança bilíngue - deve captar esses fenômenos.

Numa série de trabalhos, temos discutido um modelo para explicar esses fenômenos (LILLO-MARTIN et al., 2010; KOULIDOBROVA, 2012; LILLO-MARTIN et al., 2012; QUADROS et al., 2013). Nosso modelo (ilustrado na figura 1) adota a perspectiva de que o bilinguismo deve ser explicado usando a mesma arquitetura linguística que se aplica a monolíngues (MACSWAN, 2000, 2005). Os bilíngues simplesmente adicionam material para trabalhar, mas eles devem aderir às possibilidades gramaticais disponíveis, bem como às restriçôes impostas a qualquer língua. Partimos de uma perspectiva gerativista, incorporando conceitos da morfologia distribuída (HALLE \& MARANTZ, 1993; CHOMSKY, 1995). O input de uma derivação contém raízes abstratas e morfemas. Para o bilíngue, há dois conjuntos de itens para serem escolhidos durante a derivação. Na sintaxe, os traços devem estar satisfeitos; e, em alguns casos, os elementos da língua A podem satisfazer os requisitos dos elementos da língua , permitindo estruturas com influência ou transferência interlinguística. No ponto da Inserção do Vocabulário, os elementos podem ser tanto de uma língua como de outra, caso todos os requisitos sejam satisfeitos, permitindo a alternância de línguas. Também, quando dois conjuntos independentes de línguas tiverem articuladores independentes, os itens lexicais de ambas as línguas são possíveis, viabilizando a sobreposição. Todos os três fenômenos 
são consequências naturais do nosso modelo de Síntese, chamado assim porque oferece um quadro de possibilidades combinatórias permitidas pela arquitetura da linguagem.

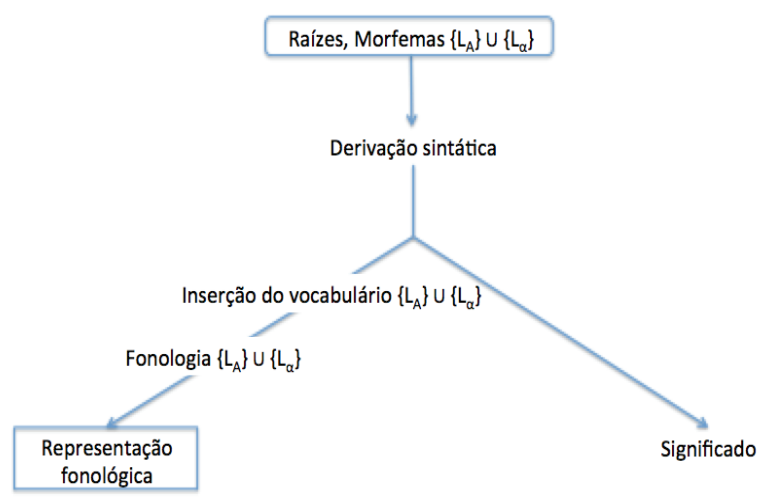

FIGURA 1. Modelo de Síntese (LILLO-MARTIN et al., 2012; QUADROS et al., 2013)

Nosso projeto se propõe a verificar se este modelo consegue explicar o desenvolvimento bilíngue bimodal. Nós temos verificado que crianças ouvintes, adquirindo uma língua de sinais e uma língua falada (kodas - com ' $\mathrm{k}$ - que refere à 'kids' - crianças de pais surdos), vão ter produçôes que são previstas no modelo de síntese: transferência, alternância e sobreposição de línguas. Considerando que sobreposição de línguas é uma opção disponível ao bilíngue bimodal, não disponível a bilíngues unimodais, nós partimos da seguinte questão de pesquisa: será que o processo de desenvolvimento da sensibilidade ao interlocutor e a separação das línguas será diferente nesse grupo de crianças? Como as crianças kodas empregam a sobreposição na seleção das línguas? Além disso, uma vez que os pais e outros interlocutores variam no uso de sobreposição, como as crianças ajustam a modalidade da língua de acordo com a variação do input?

Neste artigo, nós estaremos discutindo sobre estas questões a partir dos dados de nosso estudo sobre o desenvolvimento bilíngue bimodal em crianças adquirindo duas línguas de diferentes modalidades em dois países. Nos Estados Unidos, as crianças estão adquirindo a língua de sinais americana (ASL) e o inglês e, no Brasil, a língua de sinais brasileira (Libras) e o português. 


\section{PESQUISAS REALIZADAS SOBRE BILÍNGUES BIMODAIS}

Como mencionado anteriormente, há alguns estudos que evidenciam que sobreposição de línguas é diferente da alternância de línguas. Os estudos indicam que a sobreposição de línguas é muito mais frequente em bilíngues bimodais do que a alternância de línguas, tanto em crianças como em adultos bilíngues bimodais (PETITTO et al., 2001; EMMOREY et al., 2008; VAN DEN BOGAERDE \& BAKER, 2009). Na categoria de sobreposição, os pesquisadores também distinguem diferentes tipos de produção. A terminologia e os critérios para essas subcategorias variam entre os autores.

Em um estudo recente de van den Bogaerde e Baker $(2005,2009)$ e Baker e van den Bogaerde (2008), as autoras identificaram quatro tipos de enunciados sobrepostos. As autoras adotam a noção de língua matriz ou língua de base, usada na literatura sobre alternância de línguas (por exemplo, MYERS-SCOTTON, 1993). As subcategorias propostas pelas autoras são as seguintes: (1) base no holandês; (2) base na língua de sinais holandesa (NGT); (3) não redundância entre línguas - mistura entre as duas línguas (ou seja, a proposição é produzida com pedaços em uma e em outra língua); e (4) sobreposição completa (redundante). Na sobreposição mista, as palavras e os sinais são produzidos simultaneamente, mas não são equivalentes e poderiam pertencer a diferentes classes de palavras. Os enunciados sobrepostos podem também omitir elementos gramaticais em uma das línguas, mas ainda serem considerados completamente redundante (sobreposição completa). É importante mencionar que van den Bogaerde e Baker não consideram o critério da vocalização na classificação da produção. Assim, os enunciados sinalizados acompanhados de articulação bucal de palavras do holandês, mesmo sem voz, foram contados como sobrepostos na computação dos dados. Ainda que alguns autores adotem este mesmo critério - por exemplo, Fung (2012) estudando sobreposição na língua de sinais de Hong Kong e Cantonês -, outros autores incluem somente produçôes realmente vocalizadas na composição da sobreposição (por exemplo: PETITTO et al., 2001; EMMOREY et al., 2008; BISHOP, 2010; CHEN PICHLER et al. 2010; DONATI \& BRANCHINI, 2013; KANTO et al., 2013; PETROJ et al., 2014).

Essas categorias se sobrepõem ao que outros pesquisadores têm analisado nas produçôes de crianças bilíngues bimodais. Petitto et al. (2001) também referem à língua matriz (ou língua acolhedora) em alguns dados de sobreposição, nos quais as crianças tendem a produzir na sua língua matriz a língua usada pelo seu interlocutor. No entanto, Petitto et al. estavam focados 
nas contribuições semânticas da sobreposição dos sinais e das palavras. Esses autores categorizaram os enunciados sobrepostos como semanticamente congruentes, nos quais os sinais e a fala apresentavam o mesmo significado, ou semanticamente incongruente, para as produções sobrepostas em sinais e na fala com informações diferentes e, ainda, com a mesma informação, mas com diferente ordenação para cada língua.

Petitto et al. (2001) analisaram as sobreposiçōes incongruentes produzidas pelas crianças bilíngues bimodais (11\% das alternâncias e sobreposiçōes dos enunciados), identificando que elas combinam os sinais e as palavras faladas de forma apropriada do ponto de vista semântico para criar uma única proposição coesa. Além disso, nas sobreposiçōes com a mesma informação, quando as crianças produziram fragmentos equivalentes de sinais e palavras com diferentes ordenaçōes, elas escolheram ordens de palavras apropriadas para cada língua. Petitto et al. (2001) citaram alguns exemplos que evidenciam que a mistura bilíngue bimodal era "regida semanticamente" (2001:488) nas produções das crianças desde muito cedo, indicando que elas diferenciam as duas gramáticas e refutando a preocupação popular de que a mistura de línguas causa uma confusão linguística na criança em fase de aquisição.

Pesquisadores estudando a sobreposição de codas adultos têm proposto subcategorias que vão além do que foi descrito acima. Por exemplo, Emmorey et al. (2008) distinguiram entre sobreposição de itens individuais e sobreposição de enunciados, pois, no primeiro, um único sinal aparece ao longo de um enunciado produzido na língua falada; enquanto no segundo, há sobreposição em uma sequência de dois ou mais sinais que acompanham o enunciado falado.

Assim como Petitto et al. (2001), Emmorey et al. (2008) também apresentam uma divisão entre sobreposição semanticamente equivalente e não equivalente, mas a última categoria foi mais analisada quando a sobreposição na ASL e no inglês tiveram informações divergentes (comparada com o tipo de sobreposição mista apresentado por van den Boagaerde e Baker).

\subsection{Estudos sobre sobreposição de línguas e escolha de língua no desenvolvimento de crianças bilíngues bimodais}

Os estudos sobre escolha de língua e sobreposição de línguas em crianças bilíngues bimodais em fase pré-escolar são ainda muito incipientes, apesar do interesse no tópico por várias décadas. Há algumas investigações tais como de Griffith (1985) que apresentou um estudo longitudinal de uma criança ouvinte, filha de pais surdos americanos e com um irmão surdo mais velho. Griffith reporta que essa criança bilíngue bimodal apresentava um "modo-alternância" ou de uso com a escolha das diferentes línguas, de acordo 
com os interlocutores, já a partir de 19 meses de idade. Com o passar do tempo, o "modo" mais frequente era o usado pelo interlocutor, sinalizando mais com os sinalizantes, especialmente com o pai, e usando mais sinais associados com a fala com a mãe, que tendia a se dirigir ao filho desta forma. Griffith propôs que a criança deduzia a preferência de seus interlocutores baseado na reação ao uso da fala, ou dos sinais ou dos sinais associados à fala. Além disso, há evidências de que a criança estabelecia o "modo" em sessōes em que apareciam interlocutores completamente não familiares à criança. De maneira geral, Griffith concluiu que a criança bilíngue bimodal apresentava uma competência comunicativa desde muito cedo ao selecionar o modo apropriado de comunicação de acordo com o seu interlocutor.

Investigações mais recentes sobre sobreposição de línguas revelam um quadro mais sofisticado sobre a escolha de língua por crianças bilíngues bimodais. Em uma série de publicações sobre estudos longitudinais com base em dados de produção espontânea de crianças ouvintes holandesas com a mãe surda, van den Bogaerde e Baker $(2005,2009)$ e também Baker e van den Bogaerde (2008) apresentam padrões que não são necessariamente estáticos e em que a escolha das línguas das crianças bilíngues bimodais investigadas, interagindo com suas mães, pode mudar com o tempo. Van den Bogaerde e Baker (2009) reportam que as mães usavam muitas sobreposições com suas crianças nas três amostras coletadas longitudinalmente (quando a criança tinha $1 ; 06,3 ; 0$ e 6;0). As mães também aumentaram o uso exclusivo de língua de sinais holandesa (NGT) ao longo do tempo. As crianças bilíngues bimodais aumentaram o uso de sobreposição entre 1;06 e 6;0 em nível comparável com o de suas mães, mas o mesmo não aconteceu com a produção exclusiva em NGT. Duas das três crianças também continuaram a produzir uma grande proporção de enunciados em holandês aos 6;0 comparado ao input das mães.

Quanto ao tipo de sobreposição, as sobreposições com base no holandês foram predominantes na amostra coletada com 3;0 e mantiveramse importantes aos 6;0, mesmo que tenham desaparecido nas produçôes das mães que passaram a usar NGT como base ou sobreposiçôes completas. Van den Bogaerde e Baker concluíram que as escolhas das línguas e os tipos de sobreposição produzidos pelas crianças bilíngues bimodais podem ser parcialmente explicados com base no input. Outros fatores potenciais, como a proficiência da criança em NGT em contraste com a proficiência no holandês, a quantidade de membros surdos na família, as mudanças do ambiente linguístico (por exemplo, a entrada na escola em que apenas 
holandês é falado), como também efeitos não conclusivos diante do uso de sobreposição, podem ser fatores que compõem as decisões das crianças. Por outro lado, as autoras observaram que o grau de tolerância da mãe quanto às escolhas das crianças tem tido efeito nos usos das línguas feitos por elas. Van den Boagaerde e Baker notaram que a mãe de uma das crianças frequentemente solicitava a ela sinalizar, mesmo quando entendia perfeitamente a fala, corroborando a ideia de que a escolha da mãe pelo modo monolíngue ou bilíngue é um bom previsor das escolhas que a criança bilíngue bimodal vai fazer.

Uma conclusão similar foi feita por Kanto et al. (2013), que apresentou dados de kodas finlandeses em que os pais se dirigiam às crianças na língua de sinais. Eles concluíram que as crianças apresentaram melhor desenvolvimento na língua de sinais finlandesa (FinSL), tanto no vocabulário quanto na complexidade sintática, entre 12 e 36 meses, ao serem comparadas às crianças expostas à mistura de sinais e à fala. O primeiro grupo exposto à língua de sinais também teve interações semanais ou quinzenais com outras pessoas surdas, além dos pais, embora não tenhamos informaçôes quanto ao tipo de input dado por estes outros surdos.

Muitos dos padróes de mistura de línguas apresentados por van den Bogaerde e Baker foram também observados por Petitto et al. (2001) em três crianças bilíngues bimodais, adquirindo a língua de sinais de Québec (LSQ) e francês. Assim como com as mães holandesas, no estudo de Petitto et al. (2001), os surdos que tomavam conta das crianças também tinham produções com alternância e sobreposição de línguas. As crianças foram observadas em diferentes idades: uma delas entre 0;10-1;08; outra entre 2;10-3;04 e a mais velha entre 3;09-4;03. Elas foram filmadas interagindo com um de seus pais, assim como com um dos experimentadores, que não lhes era familiar, que se comportava como sendo monolíngue ou em francês, ou em LSQ, seguido de observação das reações da criança ao ambiente comunicativo, que tinha como língua alvo uma das línguas. Assim como suas contrapartes holandesas, os enunciados sobrepostos tiveram um percentual bem mais significativo nos enunciados dirigidos aos interlocutores bilíngues, especialmente no caso da criança mais velha. Petitto et al. (2001) explica o grau de produçóes mistas observado nas crianças diretamente proporcional às produções mistas disponíveis em seu input, citando o percentual relativamente alto de produções mistas pelos bilíngues bimodais.

No entanto, assim como van den Bogaerde e Baker (2009), Petitto $e t$ al. (2001) concluíram que os padrões de input por si só não são suficientes para predizer as escolhas das línguas entre crianças bilíngues bimodais. Elas 
citam a sensibilidade precoce às línguas de seus interlocutores e a própria preferência das crianças como fatores adicionais que podem explicar as escolhas de línguas das crianças. Os autores apresentam como argumento que a sensibilidade da criança à língua do interlocutor pode ser detectada facilmente a partir dos tipos de interações, apesar das escolhas inapropriadas observadas nos dados das crianças. Crucialmente, as crianças modificaram sua proporção relativa ao uso de uma das línguas pelos interlocutores, considerando as suas produções. Esse padrão foi especialmente evidenciado nos dados de duas crianças, quando interagiam com os experimentadores que se comportavam como monolíngues. Essas modificações nas proporções de uso das línguas ficou ainda mais evidente nas produçōes da criança mais nova. Petitto et al. (2001) explica que os casos de escolha não apropriada na LSQfrancês foram observados e que acontecem porque as crianças estão em fase de desenvolvimento. Essas escolhas têm relação com a preferência da língua e/ou lacunas lexicais temporárias, mas que não podem desconsiderar a capacidade clara que as crianças já têm de escolher a língua dependendo do seu interlocutor, apesar dos diferentes graus observados entre as crianças analisadas (2001:479).

\subsection{Estudos sobre escolha de línguas em crianças bilíngues unimodais}

Os estudos em crianças bilíngues unimodais têm demonstrado que as crianças apresentam sensibilidade às línguas de seus interlocutores em estágios precoces do seu desenvolvimento linguístico. Foi observado que as crianças usam mais a língua $\mathrm{A}$ com um interlocutor que fala $\mathrm{A}$ e usam mais a língua $\alpha$ com o interlocutor que fala $\alpha$ (GENESEE et al. 1995, PETITTO et al. 2001). Isso não significa que a criança irá usar somente A ou $\alpha$ com os falantes de $\mathrm{A}$ ou $\alpha$, respectivamente, ou ainda mais $\mathrm{A} / \alpha$ nos contextos apropriados. Como Paradis e Nicoladis (2007, p.278) sintetizam, a sensibilidade aos interlocutores, então, não é a perfeita separação da língua de acordo com o contexto do discurso (separação do discurso).

O grau da sensibilidade da criança ao interlocutor muda ao longo dos anos. No início da aquisição (antes dos 2;0), a escolha da língua pela criança pode ser atenuada pelo seu conhecimento lexical, uma vez que ela dispõe de um repertório limitado para realizar a alternância de língua e preencher as lacunas lexicais. Apesar disso, há uma tendência forte para a língua do enunciado da criança ser apropriada ao contexto já entre 1;07-1;08 (DEUCHAR \& QUAY, 1999; NICOLADIS \& SECCO, 2000). Deuchar e Quay sustentam que o conhecimento lexical precisa ser levado em consideração. 
Nicoladis e Genesse (1996), Genesee et al. (1995) e outros observaram que a criança bilíngue de 2 anos de idade geralmente demonstra sensibilidade ao interlocutor. Nesse período, há vários fatores que podem contribuir para atrapalhar a sensibilidade e a separação das línguas pela criança. Um deles é a dominância das línguas: as crianças normalmente têm uma língua mais dominante, que será usada nos contextos apropriados e que pode se sobrepor ao uso da língua não dominante em outros contextos (GENESEE et al. 1995; NICOLADIS \& GENESEE 1996). Outro fator relevante é o estilo de comunicação usado em casa. Quando os pais são mais tolerantes e indicam compreender quando a criança mistura as línguas ou escolhe a língua não apropriada, as crianças tendem a manter esse padrão. Por outro lado, as famílias que exigem a escolha de uma das línguas de acordo com o contexto, influenciam a criança a escolher a devida língua, dependendo do seu interlocutor (LANZA, 1997; DÖPKE, 1992). Isso evidencia um paralelo entre crianças unimodais e bimodais, considerando os estudos de van den Bogaerde e Baker.

Alguns estudos identificaram um alto grau de sensibilidade e controle na escolha das línguas em estágios relativamente precoces. Comeau et al. (2003) investigou seis crianças bilíngues francês-inglês, de dois anos (2;0-2;7). No seu estudo, um experimentador interagia com as crianças em três momentos distintos, modificando sua produção de alternância de línguas de 15\% do tempo na primeira sessão, para $40 \%$ na segunda e voltando a $15 \%$ na terceira sessão. Interessantemente, eles verificaram que cinco das seis crianças se enquadraram na mudança e ajustaram a quantidade de alternância de línguas na proporção do experimentador, e quase todas procuraram ajustar a forma de mistura de línguas seguindo o input do interlocutor. Esses resultados demonstram claramente a habilidade de fazer escolhas de língua de acordo com o contexto.

Um estudo examinou a sensibilidade do interlocutor de ajustar o modo com crianças um pouco mais velhas, no sentido de determinar se ocorre uma separação real dos discursos nos anos pré-escolares. Considerando a dominância de línguas, esse estudo também levou em conta o fator da comunidade dominante. Paradis e Nicoladis (2007) estudaram oito crianças entre 3;06-4;11 bilíngues inglês-francês, em uma comunidade na qual o inglês era dominante, em Alberta, Canadá. Nesse contexto, as pessoas tendem a usar mais o inglês com interlocutores falantes de inglês, bem como alguns tipos de produções mistas com interlocutores falantes de francês. Como esperado, as crianças que dominam o francês tendem a usar apenas o francês nos contextos em francês e passam a usar o inglês em contextos em 
inglês. Por outro lado, enquanto as crianças que têm o inglês como língua dominante usam o inglês em contexto virtualmente em inglês, elas tinham uma proporção menor de uso do francês nos contextos em francês. Paradis e Nicoladis (2007) sugerem que a dominância do inglês em contextos sociolinguísticos específicos favorecem esse resultado; portanto, há poucas ocorrências de mistura nos contextos em inglês. Nos contextos em francês, a mistura de línguas é mais tolerada com as crianças com um francês menos aprimorado, o que favorece o uso de construções mistas.

\subsection{O presente estudo}

Considerando os estudos anteriores com bilíngues bimodais e unimodais, o presente estudo se propôs a investigar uma série de questôes sobre a sensibilidade dos interlocutores, o papel do input e a possibilidade de misturar as línguas em contextos bilíngues bimodais.

Especificamente, os bilíngues bimodais, diferente dos bilíngues unimodais, têm a possibilidade de três modalidades de expressão: fala, sinais ou bimodal. Quando dirigindo a fala a vários interlocutores, as crianças podem usar seu conhecimento linguístico buscando captar a linguagem independentemente de cada modalidade. Por exemplo, os interlocutores surdos têm acesso restrito à língua falada, mas isso varia de pessoa para pessoa. Alguns pais surdos podem usar a fala ou sobrepor as línguas com as crianças, ou, ainda, indicar algum entendimento da fala ou da sobreposição dos enunciados. Outros podem insistir na língua de sinais ou na sobreposição, que permite que a mensagem seja apresentada tanto em sinais, como na fala. Então, para a separação completa do discurso, as crianças bilíngues bimodais provavelmente não irão usar somente sinais nos contextos em sinais, mas uma combinação de sinais e fala. Dada a possibilidade de uma separação mais completa na língua dominante para a comunidade, é possível que a criança bilíngue bimodal desenvolva, usando mais a fala nos contextos de fala, mesmo se há uma variedade de escolhas feitas em contextos na língua de sinais.

A seguir, apresentamos as questôes que nortearam a pesquisa apresentada neste artigo:

(1) As crianças bilíngues bimodais apresentam sensibilidade ao interlocutor para a seleção da modalidade de língua em diferentes níveis, dependendo da língua alvo de cada sessão? Especificamente, elas apresentam proporções maiores na língua falada nas sessões na qual a língua falada é a língua alvo? 
A hipótese nula é de que a seleção da língua pela criança não varia de acordo com o contexto (a língua alvo). Nós acreditamos que há diferenças entre a seleção das línguas de acordo com a língua alvo de cada sessão.

(2) Há alguma diferença entre as sessões nas quais a língua alvo é influenciada pela dominância da língua falada em contextos sociolinguísticos mais variados? Nós acreditamos que as crianças vão atingir o alvo nos contextos em que a língua alvo é a fala, mas não necessariamente nos contextos em que a língua alvo é a língua de sinais, assim como observado no estudo de Paradis e Nicoladis (2007).

(3) As crianças bilíngues bimodais ajustam as escolhas de línguas de acordo com os seus interlocutores? A hipótese nula seria de que não há diferença entre as crianças e seus interlocutores. No entanto, nós esperamos que as crianças não espelhem simplesmente os seus interlocutores, mas sejam influenciadas pela variedade das variáveis na sua seleção das línguas.

(4) O padrão da seleção da língua muda ao longo do desenvolvimento da criança? Nós estamos interessados na possibilidade de verificar se as crianças vão desenvolver a habilidade de separar as línguas nos estágios mais avançados de desenvolvimento. No entanto, é possível que as misturas de línguas vão continuar acontecendo, uma vez que as crianças nos estágios mais avançados de aquisição do nosso estudo ainda manifestam a mistura de línguas, uma vez que a idade de nossas crianças mais velhas é ainda considerada nova no estudo de Paradis e Nicoladis (2007).

(5) O padrão de seleção das línguas varia entre crianças americanas e crianças brasileiras? Como nosso estudo envolve crianças americanas e brasileiras, nós podemos considerar a possibilidade de diferenças específicas por razões culturais ou linguísticas. No entanto, para isso seria necessário um estudo mais amplo para identificar diferenças linguísticas e culturais.

\section{MÉTODO}

\subsection{Participantes}

Os participantes da pesquisa são quatro crianças bilíngues bimodais e os seus interlocutores. As crianças fazem parte de um estudo longitudinal do projeto 
"Desenvolvimento Bilíngue Bimodal", no qual elas foram envolvidas por meio de uma coleta por um período de até quatro anos. Três das crianças (BEN, TOM e EDU) têm os pais surdos e a quarta (IGOR) tem o pai surdo e a mãe ouvinte, fluente em língua de sinais. Todas as crianças têm acesso à língua de sinais em casa (Libras e ASL) e à língua falada com seus parentes, vizinhos e comunidade. Para este artigo, nós analisamos um subconjunto dos vídeos coletados para cada criança, focando no período de 1;06-3;06, conforme apresentado na tabela 1:

TABELA 1

Informações sobre os participantes

\begin{tabular}{|c|c|c|c|c|c|c|c|}
\hline & & & & \multicolumn{4}{|c|}{ Total \# Enunciados produzidos } \\
\hline Criança & Período & $\begin{array}{c}\text { \#sessóes } \\
\text { alvo } \\
\text { fala }\end{array}$ & $\begin{array}{c}\text { \# sessóes } \\
\text { alvo } \\
\text { sinais }\end{array}$ & $\begin{array}{c}\text { Criança, } \\
\text { sessóes } \\
\text { fala }\end{array}$ & $\begin{array}{c}\text { Criança, } \\
\text { sessōes } \\
\text { sinais }\end{array}$ & $\begin{array}{l}\text { Interlocutor, } \\
\text { sessóes } \\
\text { fala }\end{array}$ & $\begin{array}{l}\text { Interlocutor, } \\
\text { sessões } \\
\text { sinais }\end{array}$ \\
\hline $\begin{array}{l}\text { BEN } \\
\text { (US) }\end{array}$ & $\begin{array}{l}1 ; 04- \\
3 ; 06\end{array}$ & 8 & 8 & 4311 & 2672 & 4577 & 3972 \\
\hline $\begin{array}{l}\text { TOM } \\
\text { (US) }\end{array}$ & $\begin{array}{l}1 ; 05- \\
3 ; 01\end{array}$ & 4 & 5 & 941 & 1200 & 1106 & 2121 \\
\hline $\begin{array}{l}\text { EDU } \\
\text { (BR) }\end{array}$ & $\begin{array}{c}2 ; 00- \\
3 ; 03\end{array}$ & 4 & 3 & 2652 & 1180 & 2067 & 899 \\
\hline $\begin{array}{c}\text { IGOR } \\
\text { (BR) }\end{array}$ & $\begin{array}{c}2 ; 01- \\
3 ; 07\end{array}$ & 5 & 4 & 2764 & 1741 & 3142 & 1657 \\
\hline
\end{tabular}

Fonte: Dados da pesquisa.

\subsection{Coleta de dados}

Os participantes foram filmados em contextos de produção espontânea o mais natural possível, normalmente em suas casas. As sessōes de filmagem foram alternadas, dependendo da língua alvo, a língua de sinais ou a língua falada. Os interlocutores que interagiam em língua de sinais, normalmente, eram um dos pais surdos com a participação de assistentes de pesquisa surdos (em alguns casos codas), que também interagiam com a criança ou ficavam atrás da filmadora. Os interlocutores das sessōes nas quais a língua alvo era a falada, geralmente um pesquisador assistente ouvinte interagia com a criança (alguns desses ouvintes eram fluentes em língua de sinais); no caso do IGOR, a interação na língua falada foi com a mãe. Em alguns casos, um assistente de pesquisa ouvinte estava nas sessões nas quais a língua alvo era a língua de sinais, 
ou uma pessoa surda (o assistente de pesquisa ou um dos pais) estava também presente nas sessões em que a língua alvo era a falada. Nosso objetivo foi eliciar o uso das línguas naturalmente e observar a ocorrência de mistura de línguas; nós não forçamos a separação das línguas (veja Chen Pichler et al., 2013, para mais detalhes sobre a metodologia empregada durante as filmagens).

\subsection{Processamento dos dados}

O processamento dos dados acontecem em duas etapas: (1) a primeira envolve a transcrição da fala e dos sinais para constituir os corpora para a análise ser realizada (CHEN PICHLER et al. 2010; QUADROS et al. 2012; no prelo); (2) posteriormente, adicionamos a anotação específica de acordo com os objetivos da pesquisa em foco.

\subsubsection{Transcrição}

A transcrição foi feita em nossos laboratórios de pesquisa, seguindo os procedimentos e convenções descritos em Chen Pichler et al. (2010). A seguir, sintetizamos os procedimentos: o programa ELAN foi usado para fazer todas as anotações (http://tla.mpi.nl/tools/tla-tools/elan/; CRASBORN \& SLOETJES, 2008). Nosso objetivo primário é criar uma anotação de vídeos que possa ser usada em sistemas de busca e, além disso, anotar dados para atender objetivos específicos de uma determinada pesquisa. Primeiro, ouvintes assistentes de pesquisa transcrevem a fala usada pelos participantes no vídeo (a criança, o interlocutor primário, outras crianças e outros adultos, quando for o caso). A ortografia ordinária foi usada com alguns símbolos especiais, de acordo com as necessidades. Depois, assistentes de pesquisa (quase) nativos em língua de sinais para transcrever os dados em língua de sinais. Os transcritores surdos podem consultar as transcrições da fala, quando necessário. As glosas em inglês ou português foram usadas para as anotações dos sinais, incluindo algumas convenções adicionais. Tanto as anotações da fala como dos sinais foram checadas por meio de passos adicionais durante $o$ processo para serem validadas. Por fim, a tradução livre para o inglês e/ou português é adicionada, tanto para a língua de sinais como para a língua falada.

\subsubsection{Codificação}

Para a análise realizada aqui, a codificação requerida envolveu trilhas do nosso modelo básico do ELAN, com um conjunto específico às nossas 
análises para cada participante (a criança, o adulto e os demais possíveis interlocutores que apareceram em alguns casos).

-Interlocutor: o receptor (adulto surdo, o adulto ouvinte, os pais ou a criança) -Modalidade: modalidade do enunciado (somente sinais, somente fala, bimodal ou excluído)

- Tipo bimodal (somente para os enunciados bimodais): a modalidade na qual a maioria das proposições são expressadas (completamente bimodal, base na fala, base nos sinais)

Os enunciados foram excluídos se estavam ininteligíveis, ou consistiam de apenas uma palavra ou um sinal expressando rotinas, interjeições, expressões de ações comunicativas, enunciados com função fática ou imitaçôes completas do enunciado do interlocutor ou do pesquisador assistente, sem estar associado com um outro sinal ou fala. Para a análise da modalidade, os enunciados foram também excluídos caso a modalidade pudesse ser determinada; por exemplo, havia fala audível, mas as mãos do falante estavam fora do alcance da câmera. Nas análises iniciais, as combinações da fala e das interjeiçôes em sinais (por exemplo, falar 'sim' com um movimento da cabeça) foram contadas como bimodal, assim como combinações da fala com a apontação em sinais. Nas análises subsequentes, essas combinações foram excluídas da contagem bimodal.

\section{RESULTADOS}

\subsection{Análise geral}

Para a primeira análise, calculamos a proporção de sinais, da fala e dos enunciados bimodais produzidos pela criança e por seus interlocutores em todos os contextos, nas sessôes em que a fala e a língua de sinais eram alvo. Os resultados desse cálculo estão apresentados na tabela 2. Duas coisas aparecem imediatamente. A primeira: as crianças mostraram produçōes diferenciadas nas sessões em que a fala e os sinais eram alvo. Isso é confirmado com a série de quatro testes $\chi^{2} 2 \times 3$ de independência ( $\mathrm{n}$ faixa de 943-4671, $\chi^{2}=163.5-1512.58, p$ $<.0001$ para todos os quatro testes, Cramer's V $=.3123-.5683$ ). Segundo: as crianças agiram diferentemente de acordo com os seus interlocutores nos padrões das produçóes na fala, bimodal e em sinais (para sete a oito teste chi-quadrado, 
$\mathrm{n}=1356-6724, \chi^{2}=54.21-1130.18, p<.0001$, Cramer's $\mathrm{V}=.1574-.8128$;

o efeito é marginal em $\chi^{2}(2, \mathrm{n}=4813)=5.82, p=.0545$, Cramer's $\mathrm{V}=.0348$ para a comparação entre o output e input do IGOR nas sessões de fala).

TABELA 2

Resultados gerais. Proporção dos enunciados na fala, bimodal e em sinais produzidos por cada criança e interlocutor nas sessōes em sinais e na fala

\begin{tabular}{|c|c|c|c|c|c|c|c|c|c|}
\hline & \multicolumn{2}{|l|}{ BEN } & \multicolumn{2}{|l|}{ TOM } & \multicolumn{2}{|l|}{ EDU } & \multicolumn{2}{|l|}{ IGOR } \\
\hline & & Output & Input & Output & Input & Output & Input & Output & Input \\
\hline \multirow{3}{*}{$\begin{array}{l}\text { Sessões } \\
\text { Fala }\end{array}$} & Fala & 0.58 & 0.73 & 0.81 & 0.75 & 0.93 & 0.74 & 0.78 & 0.75 \\
\hline & Bimod. & 0.37 & 0.24 & 0.13 & 0.24 & 0.06 & 0.21 & 0.18 & 0.20 \\
\hline & Sinais & 0.04 & 0.03 & 0.06 & 0.00 & 0.01 & 0.05 & 0.04 & 0.05 \\
\hline \multirow{3}{*}{$\begin{array}{l}\text { Sessões } \\
\text { Sinais }\end{array}$} & Fala & 0.11 & 0.05 & 0.41 & 0.01 & 0.65 & 0.02 & 0.51 & 0.03 \\
\hline & Bimod. & 0.43 & 0.10 & 0.36 & 0.10 & 0.17 & 0.03 & 0.29 & 0.08 \\
\hline & Sinais & 0.45 & 0.85 & 0.23 & 0.89 & 0.18 & 0.96 & 0.20 & 0.89 \\
\hline
\end{tabular}

Fonte: Dados da pesquisa.

\subsection{Análise desenvolvimental}

Para analisar os padrões de mistura de línguas nos bilíngues bimodais, como sendo diferenciados de outras crianças ouvintes, nós conduzimos uma segunda análise na qual eliminamos os enunciados bimodais, quando a fala foi acompanhada da apontação, sem outro sinal (fala+apontação). Esse tipo de combinação de fala mais a apontação não é exclusivo de crianças bilíngues bimodais, pois é recorrente nas produções de crianças ouvintes, não sinalizantes (CAPIRCI et al., 1996; OZÇALISKAN \& GOLDINMEADOW, 2005), em que a apontação acompanha a fala classificada como gestual. Nossa exclusão destas ocorrências da segunda análise teve um cunho mais conservador, dado que o debate sobre o valor da apontação na linguística das línguas de sinais é ainda muito controverso. Por essa mesma razão, nós excluímos as combinaçóes que consistiam apenas de elementos isolados.

Além disso, nós separamos os enunciados que foram produzidos dirigidos a diferentes interlocutores. Nas sessões americanas ocasionalmente incluímos os diferentes interlocutores com diferentes condições auditivas. 
Focamos nas produções das crianças para os interlocutores ouvintes nas sessōes em que a fala era a língua alvo e, nos interlocutores surdos, quando a língua alvo era a língua de sinais. Nós também focamos nos enunciados dos interlocutores voltados para a criança, excluindo outros interlocutores presentes na interação. Por fim, calculamos a proporção da fala, bimodal e dos sinais em cada sessão, para observar possíveis efeitos do desenvolvimento. Os resultados estão calculados e apresentados graficamente nas figuras 2-5.

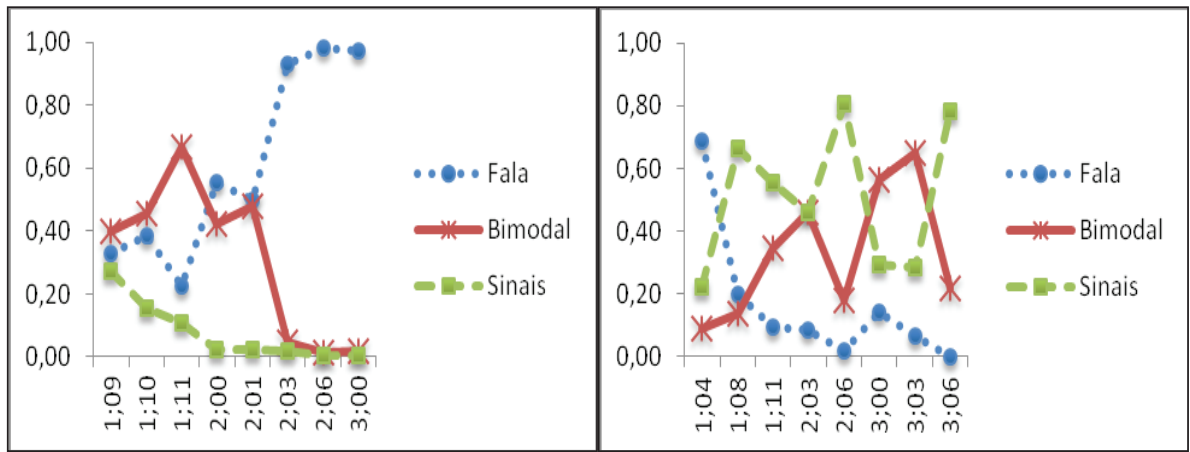

(C)

(D)

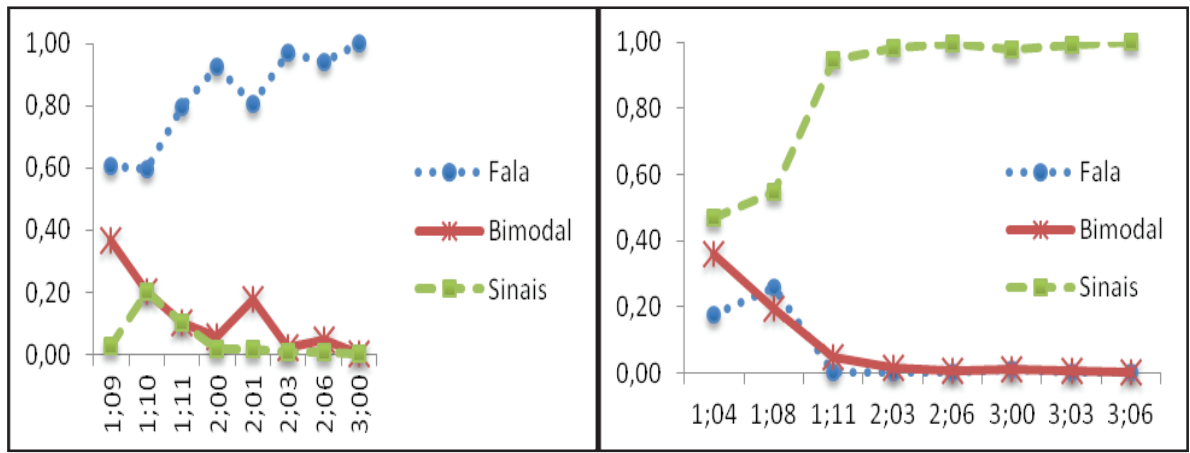

FIGURA 2 - Proporção da escolha da língua ao longo do desenvolvimento: BEN. Enunciados produzidos na fala (pontos em azul), enunciados produzidos em sinais (pontilhado verde), bimodal (asterisco vermelho): (A) output, alvo fala; (B) output, alvo sinais; (C) input, alvo fala; (D) input, alvo sinais. (Nota: Intervalos ao longo x-axis não são regulares).

Fonte: Dados da pesquisa. 
(A)

(B)

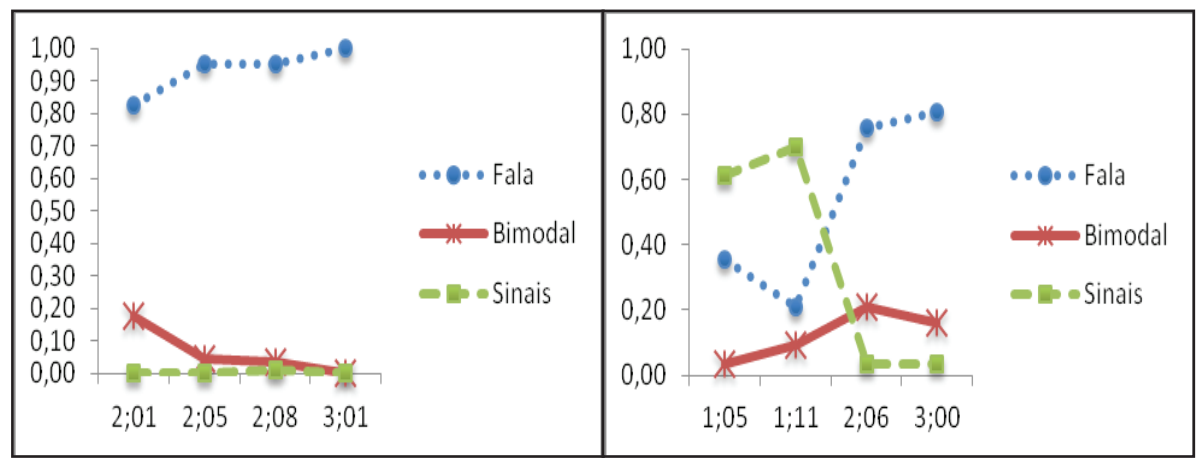

(C)

(D)

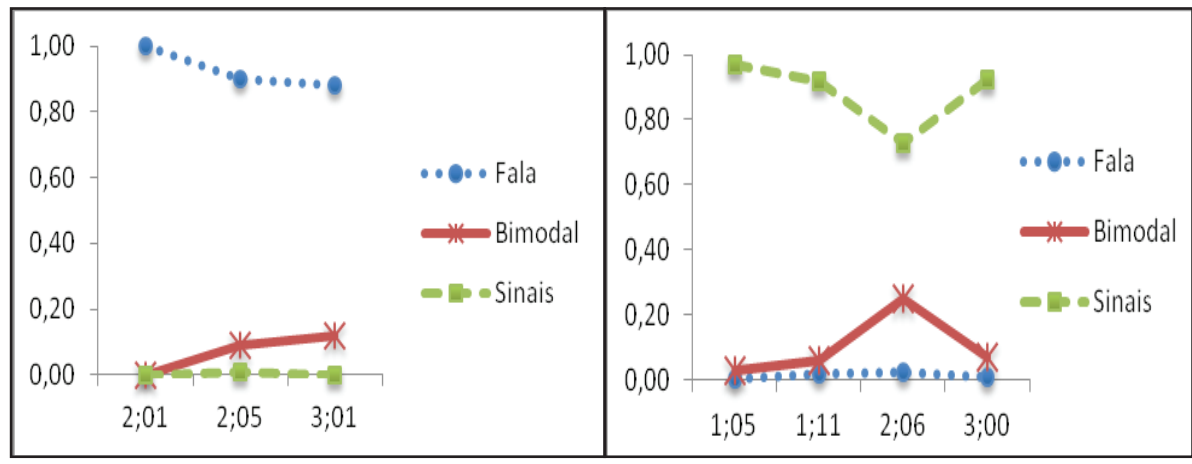

FIGURA 3. Proporção da escolha da língua ao longo do desenvolvimento: TOM Enunciados produzidos na fala (pontos em azul), enunciados produzidos em sinais (pontilhado verde), bimodal (asterisco em vermelho): (A) output, alvo fala; (B) output, alvo sinais; (C) input, alvo fala; (D) input, alvo sinais. (Nota: Intervalos ao longo x-axis não são regulares)

Fonte: Dados da pesquisa. 
(A)

(B)

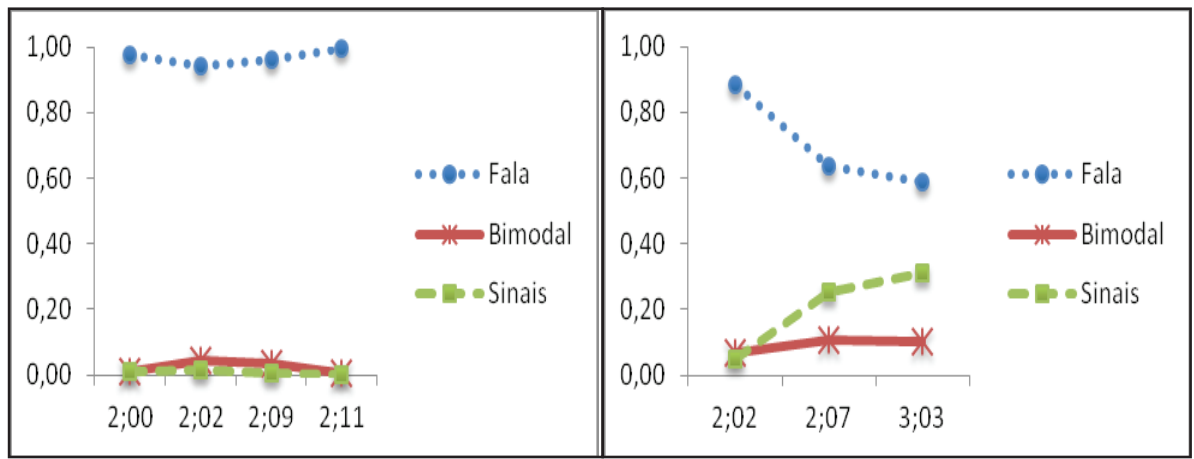

(C)

(D)

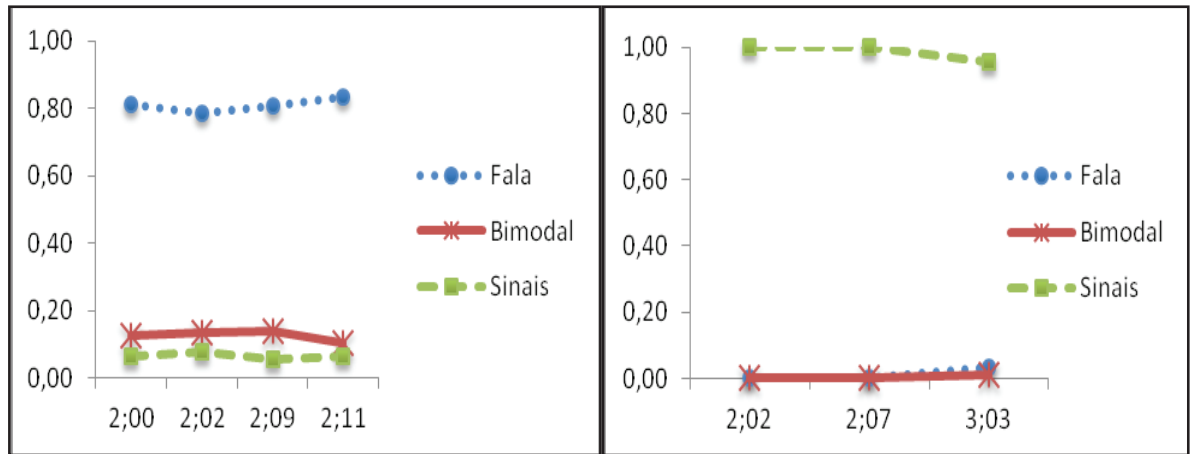

FIGURA 4. Proporção da escolha da língua ao longo do desenvolvimento: EDU Enunciados produzidos na fala (pontos em azul), enunciados produzidos em sinais (pontilhado verde), bimodal (asterisco em vermelho): (A) output, alvo fala; (B) output, alvo sinais; (C) input, alvo fala; (D) input, alvo sinais. (Nota: Intervalos ao longo x-axis não são regulares)

Fonte: Dados da pesquisa. 


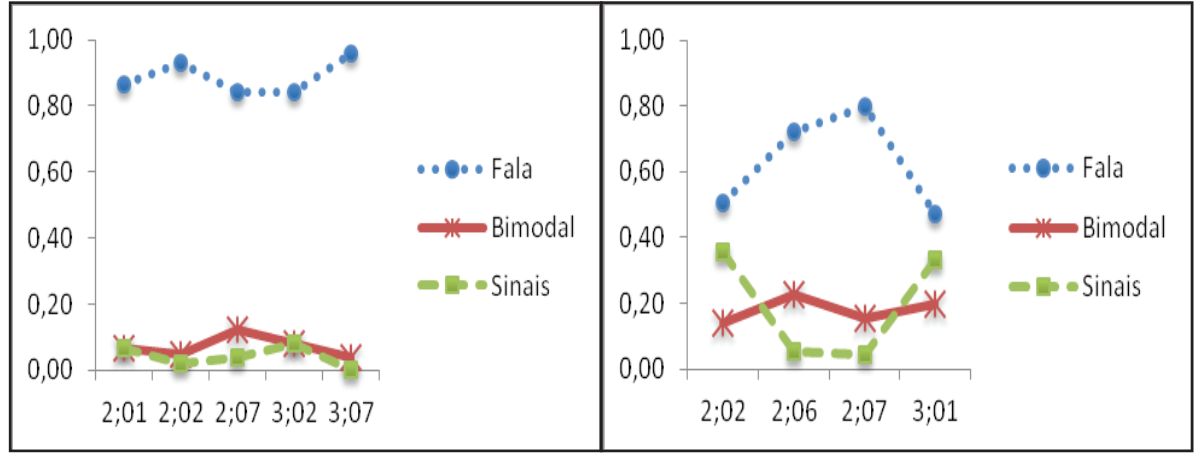

(C)

(D)

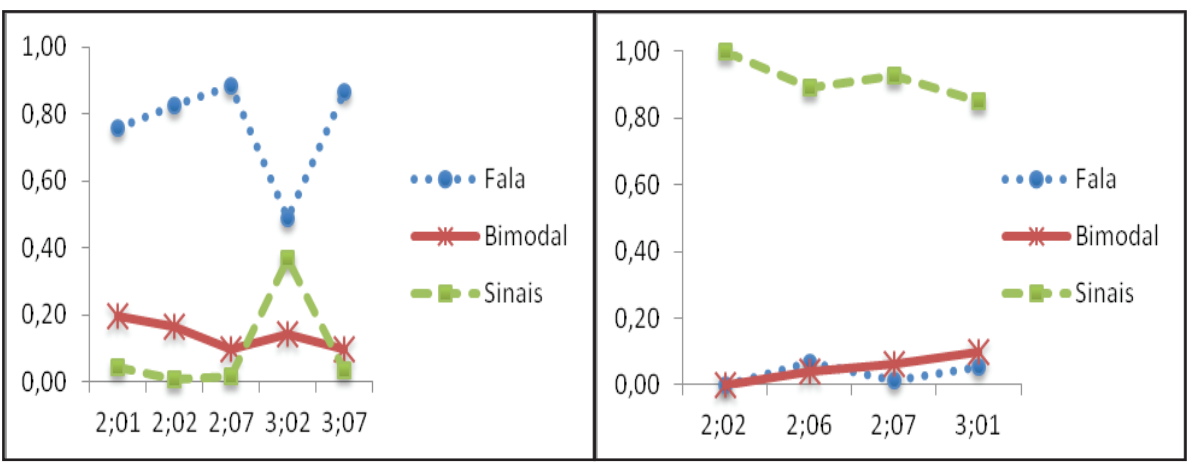

FIGURA 5. Proporção da escolha da língua ao longo do desenvolvimento: IGOR. Enunciados produzidos na fala (pontos em azul), enunciados produzidos em sinais (pontilhado verde), bimodal (asterisco em vermelho): (A) output, alvo fala; (B) output, alvo sinais; (C) input, alvo fala; (D) input, alvo sinais. (Nota: Intervalos ao longo x-axis não são regulares)

Fonte: Dados da pesquisa.

Uma série de testes $\chi^{2}$ foi aplicada para verificarmos se o padrão de modalidade (fala, bimodal e sinais) produzidos por cada criança foi diferente do que os produzidos pelos interlocutores na mesma sessão. Uma segunda série de teste $\chi^{2}$ examinou as diferenças entre cada criança nas produçôes nas sessóes em que fala ou os sinais eram alvo, comparando-se em diferentes idades. Os resultados dessas comparações são apresentados individualmente para cada criança, a seguir:

$\mathrm{BEN}$. Seis comparaçóes de $\chi^{2}$ entre o BEN e seus interlocutores foram feitas nas sessões de fala: para quatro das cinco comparações $n=432$ - 911, 
$\chi^{2}=30.56-337.97, p<.0001$, Cramer's $V=.266$ - .6091; .uma comparação $(2 ; 03)$ foram marginal $\left(\mathrm{n}=773, \chi^{2}=5.53, p=.063\right.$, Cramer's $\left.\mathrm{V}=.0846\right)$. Sete das comparaçōes $\chi^{2}$ entre BEN e seus interlocutores foram feitas em sessōes em que a língua de sinais é a língua alvo.

Sete comparações $\chi^{2}$ entre BEN e seus interlocutores foram feitas nas sessões em que a língua de sinais era a língua alvo: $\mathrm{n}=147-771, \chi^{2}$ $=6.98-410.71, p<.0001$ para seis das comparações e $=.03$ para a sétima (1;08), Cramer's $V=.1073-.7510$. Para uma sessão $(2 ; 06)$, duas ou mais frequências esperadas foram calculadas menores que 5 , assim o teste $\chi^{2}$ não pode ser conduzido.

Para comparar a produção do BEN, das sessões na fala versus de sinais, nós categorizamos suas sessōes em quatro grupos: (a) menos de dois anos; (b) dois anos; (c) dois anos e meio; (d) três anos para cima. Quatro testes $\chi^{2}$ deram os seguintes resultados: $\mathrm{n}=880-1169, \chi^{2}=181.39-879.36, p<.0001$ para todos os quatro, Cramer's V $=.4190-.9597$.

TOM. Duas comparaçôes $\chi^{2}$ entre TOM e seus interlocutores foram feitas para as sessões na fala. Somente uma alcançou significância $(3 ; 01): \chi^{2}$ $(2, \mathrm{n}=297)=22.93, p<.0001$, Cramer's $\mathrm{V}=.2779$. Em contraste, com $2 ; 05$ não foi significante $\left(\chi^{2}(2, \mathrm{n}=813)=4.33, \mathrm{p}=.1147\right.$, Cramer's $\left.\mathrm{V}=.073\right)$. Para uma sessão na fala $(2 ; 01)$, duas ou mais frequências foram calculadas menores que 5 . Por causa do número total de observações ser menor de 300, o teste exato Fisher foi aplicado: $\mathrm{n}=23, p=.5392$.

Duas comparações $\chi^{2}$ entre TOM e seus interlocutores foram feitas nas sessões em sinais: $\mathrm{n}=312-446, \chi^{2}=205.77-362.66, p<.0001$ para ambos, Cramer's $V=.8121-.9017$. Para as duas sessões em sinais de 1;05 e 1;11, duas ou mais frequências foram calculadas menores de 5 . Para uma dessas sessões, 1;11, o número total de observaçôes foi menor que 300, assim o teste exato Fisher foi aplicado: $\mathrm{n}=93, p=.0089$.

Para comparar a produção de TOM nas sessões de fala versus de sinais, nós caracterizamos suas sessões em três grupos: (a) dois anos; (b) dois anos e meio; (c) três anos. Um teste $\chi^{2}$ foi aplicado para a sessão de dois anos: $\chi^{2}$ $(2, \mathrm{n}=60),=24.58, p<.0001$, Cramer's $\mathrm{V}=.6401$. Para as comparaçôes entre duas sessões de sinais e fala (dois anos e meio e três), duas ou mais frequências foram calculadas menores de 5 . O teste exato Fischer foi aplicado nestes casos: $\mathrm{n}=217, p=.00003 ; \mathrm{n}=320, p=2.13 \mathrm{e}-10$ (para esta última comparação, o número de observações na célula mais alta foi reduzido de 181 para 161 para se chegar ao total de observações abaixo de 300 ). 
EDU. Quatro comparaçōes $\chi^{2}$ entre o EDU e seus interlocutores foram feitas nas sessões na fala: $\mathrm{n}=786-958, \chi^{2}=47.52-80.80, p<.0001$ para todas as quatro, Cramer's $\mathrm{V}=.2393-.2930$. Três $\chi^{2}$ comparações entre o EDU e seus interlocutores foram feitas nas sessões em sinais: $\mathrm{n}=484-603$, $\chi^{2}=216.88-555.52, p<.0001$ para todas as três, Cramer's V $=.6694-.9598$.

Para comparar a produção do EDU nas sessões na fala e em sinais, nós categorizamos suas sessões em dois grupos: (a) dois anos; (b) três anos. Os testes $\chi^{2}$ foram aplicados: $\mathrm{n}=1200-1501, \chi^{2}=22.95-350.85, p<.0001$ para ambos, Cramer's V $=.1383-.4835$.

IGOR. Cinco comparações $\chi^{2}$ entre IGOR e seus interlocutores foram feitas para as sessōes na fala, quatro foram significantes: $\mathrm{n}=649-1152, \chi^{2}=$ $27.01-98.59, p<.0001$ para todos os quatro, Cramer's $\mathrm{V}=.1630-.3898$. $\mathrm{O}$ contraste em 2;07 não foi significativo $\left(\chi^{2}(2, \mathrm{n}=1079)=5.23, p=.0732\right.$, Cramer's V = .0696).

Quatro comparações $\chi^{2}$ entre IGOR e seus interlocutores foram feitas nas sessóes em sinais: $\mathrm{n}=391-751, \chi^{2}=171.21-426.31, p<.0001$ para todos os quatro, Cramer's V $=.5544-.8939$.

Para comparar a produção de IGOR nas sessões na fala e em sinais, nós categorizamos suas sessões em três grupos: (a) dois anos; (b) dois anos e meio; (c) três anos para cima. Três testes $\chi^{2}$ foram aplicados: $\mathrm{n}=925-1101$, $\chi^{2}=12.01-224.95, p<.0001$ para dois e $=.0025$ para o terceiro, Cramer's $\mathrm{V}=.1139-.4543$.

Sintetizando: com poucas exceções, todas as comparações apresentaram diferença significativa entre as crianças e seus interlocutores, e entre as sessões na fala e em sinais de cada criança.

\section{DISCUSSÃO}

Vamos interpretar os resultados de nossas análises retomando nossas questōes de pesquisa apresentadas na seção 2.3:

As crianças bilíngues bimodais apresentam sensibilidade ao interlocutor para a seleção da modalidade de língua em diferentes níveis dependendo da língua alvo de cada sessão? Especificamente, elas apresentam proporções maiores na língua falada nas sessões na qual a língua falada é a língua alvo? Nós previmos que, contra a hipótese nula, as crianças diferem entre a seleção das línguas de acordo com a língua alvo de cada sessão. Nossa previsão para esse caso foi confirmada pela análise apresentada na tabela 2. As crianças diferem na seleção das línguas de acordo com o contexto, com cada 
criança produzindo mais fala nas sessóes em que a língua alvo era a língua falada, comparado às sessões em que língua alvo era a língua de sinais, e elas produzem mais sinais nas sessões em sinais do que nas sessões de fala.

Há alguma diferença entre as sessões nas quais a língua alvo é influenciada pela dominância da língua falada em contextos sociolinguísticos mais variados? Nós esperávamos que as crianças fariam a escolha da língua respectiva nos contextos em que a língua alvo é a fala, mas não necessariamente nos contextos em que a língua alvo é a língua de sinais. Isso também foi confirmado. Analisando os resultados apresentados na tabela 2, verificamos que cada criança apresenta uma proporção maior de produção de fala nas sessões em que a língua alvo é a fala, comparados com as sessōes em sinais, em que tiveram uma proporção de sinais menor. De modo geral, três crianças (TOM, EDU e IGOR) tiveram um uso da fala acima de $75 \%$ nas sessões de fala, mas menos de $25 \%$ de produções em sinais nas sessões em sinais. Essa proporção também foi observada em bilíngues que tinham inglês como língua dominante no estudo de Paradis e Nicoladis (2007).

As crianças bilíngues bimodais ajustam as escolhas de línguas de acordo com os seus interlocutores? A hipótese nula seria de que não há diferença entre as crianças e seus interlocutores, mas nossa análise revela que há uma diferença significativa (tabela 2). Das oito comparaçôes entre as quatro crianças e seus interlocutores nas sessões de fala e em sinais, sete foram significativamente altas e uma delas foi marginal (na fala de IGOR). No entanto, analisando os números apresentados na tabela 2, fica claro que os padrões de uso das crianças estão mais próximos aos de seus interlocutores nas sessões de fala, do que nas sessões em sinais. Além disso, os valores de Cramer's V são muito mais altos nas sessões em sinais (entre .4222 - .8128) do que nas sessôes de fala (entre $.1574-.2623$ para os três resultados significativos), indicando que as diferenças entre as crianças e seus interlocutores são mais altas nas sessões em sinais. Esses resultados nos dão uma indicação sobre a escolha das línguas pelas crianças, que está relacionada com o conhecimento das duas línguas e seus usos apropriados de acordo com o contexto. Nós vamos retornar a esse ponto na discussão da questão 4 , a seguir.

O padrão da seleção da língua muda ao longo do desenvolvimento da criança? Para essa questão, nós nos deportamos para a análise desenvolvimental apresentada na seção 4.2 e nos gráficos das figuras 2-5. Assim como indicado nos gráficos, as escolhas das crianças mudou ao longo 
do tempo, mas de diferentes formas para cada criança. A seguir, apresentamos as discussões considerando cada criança individualmente.

BEN. Os resultados apresentados na figura 2 mostram que nas sessões de fala de BEN o uso de sinais começou relativamente baixo e teve um declínio rápido, até chegar a zero na idade de 2;00, mas o seu uso de enunciados bimodais continuou a aparecer nas sessōes de fala, até por volta de 2;03; deste ponto em diante, ele separa as línguas nos discursos em que a língua alvo é a fala. É interessante notar que o uso de sinais por seus interlocutores e de enunciados bimodais também iniciou mais alto nas sessões iniciais, chegando a zero por volta dos 2;00 e bimodal por volta dos 2;03. Nesse sentido, tanto BEN como seus interlocutores tiveram uma produção similar, mas não está claro se o uso por BEN de sinais e produções bimodais encorajou seus interlocutores a usar essas modalidades ou o inverso. Nós percebemos que por volta de 2;03, a comparação estatística não apresentou diferença significativa entre o $\mathrm{BEN}$ e seus interlocutores nas sessões de fala (foi marginal em $p=.063$ ) e, nos dois últimos anos, o teste ${ }^{2}$ não pode ser aplicado porque as frequências foram baixas - isso tem relação com a pouca quantidade de sinais tanto por BEN como por seus interlocutores. Então, BEN claramente atingiu o mesmo padrão da produção de seus interlocutores (somente usando a fala). O quadro é diferente quanto analisamos as sessões em sinais de BEN. Primeiro, nós observamos que a mãe de BEN (a interlocutora primária em quase todas as sessões em sinais, exceto na última) impetrou uma mudança notável nas suas produçōes. De fato, ela nos reportou que usava originalmente a fala associada aos sinais com seu filho ouvinte, mas que decidiu usar apenas sinais quando BEN estava com $1 ; 11$. Os dados das sessões analisadas indicam que ela realmente assumiu esta postura. $\mathrm{O}$ uso da fala nas sessôes em sinais de $\mathrm{BEN}$ indicam que ele mudou dramaticamente dos períodos inicias para os períodos depois de 1;11. No entanto, BEN não parou de usar a fala nas sessões em sinais, mas passou a usar uma mistura de línguas com produções bimodais e o uso de sinais. A proporção de sinais e produçôes bimodais variou muito.

Nas sessões de fala, os enunciados bimodais de BEN foram marcados de forma extensa como 'bimodal completa' (a proporção completa está expressa tanto em sinais como na fala). As proporções de cada tipo bimodal mudou em 2;03, mas precisamos lembrar que neste ponto os enunciados bimodais diminuíram (tem menos de 15 enunciados bimodais nas três últimas sessões). Nas sessōes em sinais, as produçōes na forma 'bimodal completa' 
foram predominantes. Esse padrão mudou somente na última sessão, em 3;06, quando o tipo bimodal foi de base sinal. Então, de 1;08 até 3;06, a maioria das produções de BEN foram somente em sinais, ou na forma bimodal com acesso completo pelos interlocutores que usavam apenas a ASL. Considerando isso, as produções bimodais de BEN foram apropriadas e evidenciam a adequação da escolha de línguas de acordo com o discurso.

TOM. O padrão dos resultados de TOM estão sintetizados nos gráficos da figura 3 e evidenciam que ele teve uma tendência em usar mais a fala nas sessões de fala em todo o seu desenvolvimento. Seus interlocutores evidenciaram uma leve tendência em usar mais produções bimodais ao longo do tempo. É esse uso que levou a uma diferença significativa entre o TOM e seus interlocutores, nas sessões de fala, mesmo que nas duas primeiras sessões essa diferença não tenha sido significativa (notem que com 2;01, nem TOM e nem os seus interlocutores produziram muitos enunciados que foram incluídos na segunda análise, pois tinham vários participantes nas sessōes e nós tivemos que excluir muitos enunciados). Nas sessões em sinais, os interlocutores de TOM usaram a língua de sinais, mas houve uma evolução no uso de produções bimodais por parte de sua mãe, sua interlocutora primária na sessão com 2;06. Nossas observaçóes informais sugerem que a mãe de TOM usou produções bimodais com seu filho e outras pessoas, assim, não tomamos isso como uma representação equivocada de seu input em geral. As produções de TOM nas sessões em sinais contaram com uma evolução nas produções faladas e bimodais, com decréscimo nas produções em sinais. Então, com 3;00 TOM apresentou uma forte tendência no uso da fala tanto nas sessões faladas como em sinais, mesmo distinguindo entre os dois contextos. Temos que manter em mente que o número total de produçóes bimodais foram menores, tanto nas sessōes em sinais como nas sessôes na fala; assim, as proporçôes de cada tipo foram interpretadas de acordo com isso. O número maior de produções bimodais aparece nas sessões em sinais de 2;06 e 3;00, em que a maioria foi 'bimodal completa'. Então, apesar de TOM não produzir uma proporção alta de enunciados bimodais, ele pode ter sido levado a substituir as produçôes em sinais por produções bimodais.

EDU. O padrão de seleção de línguas do EDU está apresentado na figura 4, apresentando uma mudança pequena ao longo do tempo, nas sessōes na fala. O seu uso de produções faladas foi alto em todas as sessões, apesar de baixo e correspondentemente alto de produções em sinais e bimodais nas sessōes em sinais, por parte de seus interlocutores. Nas sessões em sinais, o 
EDU começou a ter um uso mais produtivo da fala, mas isso foi diminuindo ao longo do tempo, passando a ter um uso mais frequente de sinais, com poucas produções bimodais. Os interlocutores nas sessões em sinais - sua mãe e seu pai surdos - usaram sinais quase de forma exclusiva na frente da câmera, mas foi observado que a sua mãe usa produções bimodais e a fala em outros momentos. Mantendo isso em mente, o número de produções bimodais foi baixo (menos de 40 em cada sessão). A distribuição dos tipos bimodais do EDU indica que a maioria de suas produções bimodais foram de base na fala, tanto nas sessóes faladas como em sinais. De modo geral, o EDU apresenta uma forte tendência em produzir seus enunciados na fala.

IGOR. O desenvolvimento do IGOR está apresentado na figura 5, evidenciando certa constância com uso de produçôes na fala bastante alto nas sessões faladas. Como o EDU, o IGOR usou mais a fala do que seus interlocutores, que também usaram produçôes bimodais (com um aumento inexplicável no número de produções em sinais na sessão com 3;02). Nas sessões em sinais, o IGOR usou uma mistura de fala, sinais e produçôes bimodais. Ele aumentou o número de sinais e diminuiu as produçóes faladas no final do período observado $(3 ; 01)$. Seus interlocutores usaram uma proporção alta de produções em sinais, com algumas produções bimodais. Os tipos de produção bimodal apresentam várias produções do tipo 'bimodal completa' e de 'base na fala'. Apesar dos detalhes da produção de IGOR serem diferentes, ele apresenta uma preferência pela fala, assim como o EDU, com um movimento na direção de usar mais sinais e produções bimodais nas sessóes em sinais, depois dos 3 anos de idade.

Todas as quatro crianças apresentaram um aumento no uso de produções bimodais com base na fala nas sessões faladas. Isso reflete um aumento na sensibilidade à fala, enquanto língua relevante, e um desenvolvimento na sofisticação das estruturas usadas na fala nas sessões faladas. Como as estruturas faladas começam a ser mais sofisticadas nas sessões faladas, elas se tornam mais longas e complexas, dificultando a produção bimodal completa nas duas modalidades. Em contraste, apesar do aumento da complexidade do conhecimento em sinais, a produção de base em sinais foi menos frequente, com exceção da última sessão do BEN (3;06).

$\mathrm{Na}$ verdade, as produções com base na fala parecem mais comuns do que as produções de base em sinais nos enunciados bimodais, tanto em jovens como em adultos codas (MALLORY et al. 1993; EMMOREY et al. 2008; PIZER 2008). De maneira geral, as produções bimodais de base em 
sinais foram incomuns e até foram rejeitadas porque a fala não parece ser uma produção típica da língua falada, implicando na rejeição de seu uso por bilíngues bimodais. Isso é consistente com nossa observação de que os interlocutores raramente usaram produçōes bimodais de base em sinais nas sessões em sinais. As produções unimodais e bimodais de kodas do nosso estudo refletem os padrões gerais a que estão expostos, mesmo que as proporçôes dos enunciados unimodais e bimodais não sejam as mesmas dos seus interlocutores.

(5) O padrão de seleção das línguas varia entre crianças americanas e crianças brasileiras? Como nosso estudo envolve apenas quatro crianças (duas americanas e duas brasileiras), ficou difícil distinguir efeitos linguísticos ou culturais de diferenças individuais. De modo geral, nossa impressão é de que o TOM, o EDU e o IGOR apresentam similaridades na performance, enquanto crianças que favorecem a língua falada e, portanto, evidenciam uma separação discursiva mais clara em relação à língua falada, mas também há sensibilidade ao interlocutor para a língua de sinais. Somente o BEN apresentou evidência de separação discursiva para ambas as línguas, mas isso é uma diferença individual. Não há como afirmamos que há diferenças decorrentes das línguas e das culturas envolvidas diante dos dados que analisamos.

\section{CONCLUSÕES}

De acordo com o modelo apresentado na figura 1, os bilíngues dispõem da opção de usar o conhecimento gramatical e lexical para ambas as línguas, tanto em separado como de forma combinada, desde que as restriçōes quanto à estrutura linguística sejam satisfeitas. Restrições adicionais podem ser impostas ao uso de mistura de línguas (incluindo a sobreposição das línguas) por questôes de ordem sociolinguística: algumas comunidades podem se aproveitar do uso da mistura de línguas entre aqueles que sejam bilíngues, enquanto outras procuram evitá-las. Então, as crianças devem aprender a levar esses fatores em consideração, ou seja, os fatores de ordem estrutural, bem como os fatores sociolinguísticos, para decidir como usar as línguas que têm disponíveis.

As crianças do nosso estudo demonstraram que elas são sensíveis aos seus interlocutores, apresentando diferenças na seleção das línguas observadas de forma contrastiva entre as sessões em que uma das línguas, a língua falada ou a língua de sinais, era a língua alvo. Três das quatro crianças evidenciaram 
que a língua falada éa língua dominante, uma vez que essa éa língua usada na grande maioria da comunidade sociolinguística em que convivem. A quarta criança, o BEN, apresentou padrões mais balanceados entre as duas línguas, demonstrando separação completa entre os discursos nas duas línguas, se contarmos o uso de sobreposição como apropriada nas sessões em que a língua de sinais era a língua alvo.

Podemos levantar uma possível questão em relação à produção de BEN nas sessões em sinais: por que o BEN não usa exclusivamente a língua de sinais em sessōes em que essa é a língua alvo? Emmorey et al. (2008) e Pyers e Emmorey (2008) observaram codas adultos e verificaram que eles usam a sobreposição de línguas, bem como marcações não manuais associadas à língua de sinais, enquanto falam, mesmo quando conversando com pessoas que não conhecem a língua de sinais. Eles concluíram que isso acontece porque é mais difícil inibir ou suprimir o uso da língua não selecionada, uma vez que isso exige um alto custo de processamento cognitivo. Para os bilíngues unimodais, o uso de uma das línguas exige a inibição da outra língua, enquanto que para bilíngues bimodais isso não é uma exigência, uma vez que eles podem usar as duas línguas.

Nós acreditamos que essa tendência a sobrepor as línguas por razões relacionadas à não necessidade de aplicar um esforço de processamento para inibir uma das línguas explica o uso de sobreposições por BEN, nas sessões em que a língua alvo é a língua de sinais. $\mathrm{O}$ mesmo pode explicar o tipo de produções observadas nas demais crianças, mesmo que os demais tenham usado muito menos sobreposições, quando comparados ao BEN.

Apesar de as crianças apresentarem sensibilidade aos seus interlocutores, elas não refletem o padrão das produções de seus interlocutores (a quantidade de enunciados falados, sinalizados e sobrepostos). É possível que as atitudes das crianças em relação ao input dado pelos seus interlocutores apresentem um papel na seleção das línguas, como sugerido por Döpke (1992) e Lanza (1997) para bilíngues bimodais, bem como por van den Bogaerde e Baker (2009) para os bilíngues bimodais de NGT e holandês. Em geral, as crianças de nosso estudo estão expostas às sobreposições de línguas desde muito cedo, por pelo menos um de seus pais, assim como estão expostos ao uso exclusivo da língua de sinais. Também observamos que todos os pais são bilíngues e usam alguns indícios da fala, em maior ou menor quantidade com seus filhos ouvintes. Muitos deles também demonstraram compreender a fala de seus filhos: por exemplo, a mãe do EDU responde (em sinais) todas as questões do EDU produzidas na fala, mostrando que ele pode ter a comunicação bem 
sucedida com sua mãe mesmo usando apenas a fala. Além disso, durante as sessōes, as crianças interagiam com outras pessoas ouvintes que sabiam a língua de sinais, o que favorecia o uso de sobreposição das línguas. $\mathrm{O}$ único caso que tinha um modelo monolíngue foi o de BEN, pois sua mãe usava consistentemente somente a língua de sinais.

Mais pesquisas são necessárias para confirmar o que constatamos com essas crianças, mas, de modo geral, os resultados encontrados indicam o que os demais pesquisadores têm concluído quanto à separação das línguas de acordo com o contexto discursivo, favorecendo a estratégia monolíngue. Além disso, assim como Chen Pichler et al. (2014) discutem, a manutenção de uma língua que representa uma minoria linguística para kodas pode ser sustentada por meio de oportunidades em usar essa língua com outros interlocutores, incluindo pares dessas crianças, ao longo do seu desenvolvimento. Assim, nós encorajamos os pais surdos que desejam ter seus filhos ouvintes bilíngues bimodais fluentes em língua de sinais a exporem seus filhos à língua de sinais com outras pessoas surdas, incluindo crianças surdas, indo além dos seus usos em casa e da língua falada, à qual elas estão amplamente expostas.

\section{Agradecimentos}

A presente pesquisa contou com o financiamento da National Institute of Health - NIH (National Institute on Deafness and Other Communication Disorders - NIDCD), projeto R01DC009263. O conteúdo apresentado é de responsabilidade exclusiva dos autores e não necessariamente representa a posição da NIH e da NIDCD. A pesquisa também contou com financiamentos parciais da Gallaudet Research Institute (projeto \#200031/2009-0) e do CNPQ (Conselho Nacional de Desenvolvimento Científico e Tecnológico, projeto \#470111/2007-0).

Nós agradecemos imensamente aos participantes da pesquisa e às suas famílias, pela paciência em nos receber ao longo de até quatro anos, pois, sem isso, não seria possível desenvolver as pesquisas apresentadas neste artigo. Agradecemos também a todos os pesquisadores assistentes que contribuíram na coleta e transcrição dos dados em sinais e na fala, bem como aos comentários preciosos de Marie Coppola, Carina Rebello Cruz, William Snyder, Jon Sprouse e aos participantes de encontros na University of Connecticut e do Encontro Anual da Sociedade Linguística Americana (Minneapolis, 2014), no qual Carol Padden sugeriu que as sobreposiçōes com base em sinais seriam evitadas devido à fala atípica produzida. 


\section{REFERÊNCIAS}

BAKER, A. \& van den BOGAERDE, B. "Code-mixing in signs and words in input to and output from children," in Sign Bilingualism: Language Development, Interaction, and Maintenance in Sign Language Contact Situations, eds. C. Plaza Pust \& E. Morales Lopez (Amsterdam: John Benjamins), 2008. 1-28.

BHATIA, T.K. \& RITCHIE, W.C. "The bilingual child: Some issues and perspectives," in Handbook of Child Language Acquisition, eds. W.C. Ritchie \& T.K. Bhatia (San Diego, CA: Academic Press), 1999. 569-643.

BHATT, R. \& BOLONYAI, A. Code-switching and the optimal grammar of bilingual language use. Bilingualism: Language and Cognition 14(4), 2011, 522-546. BISHOP, M. \& HICKS, S. Orange eyes: Bimodal bilingualism in hearing adults from Deaf families. Sign Language Studies 5(2), 2005. 188-230.

BISHOP, M. Happen can't hear: An analysis of code-blends in hearing, native signers of American Sign Language. Sign Language Studies 11(2), 2010, 205-240. CAPIRCI, O.; IVERSON, J.M.; PIZZUTO, E. \& VOLTERRA, V. Communicative gestures during the transition to two-word speech. Journal of Child Language 23, 1996, 645-673.

CHEN PICHLER, D.; HOCHGESANG, J.; LILLO-MARTIN, D. \& QUADROS, R.M. Conventions for sign and speech transcription of child bimodal bilingual corpora in ELAN. Language, Interaction and Acquisition 1, 2010, 11-40. CHEN PICHLER, D.; LEE, J. \& LILLO-MARTIN, D. "Language Development in ASL-English Bimodal Bilinguals," in Multilingual Aspects of Signed Language Communication and Disorder, ed. David Quinto-Pozos (Bristol, UK: Multilingual Matters), 2014, 235-260.

CHEN PICHLER, D.; HOCHGESANG, J.; LILLO-MARTIN, D.; QUADROS, R.M. \& REYNOLDS, W. Best practices for building a bimodal bilingual child language corpus. 2013. http://bibibi.uconn.edu/Publications.html

CHOMSKY, N. The Minimalist Program. Cambridge: The MIT Press, 1995.

COMEAU, L.; GENESEE, F. \& LAPAQUETTE, L. The modeling hypothesis and child bilingual codemixing. The International Journal of Bilingualism 7(2), 2003, 113-126.

COSTA, A. \& SANTESTEBAN, M. Lexical access in bilingual speech production: Evidence from language switching in highly proficient bilinguals and L2 learners. Journal of Memory and Language 50, 2004, 491-511.

CRASBORN, O. \& SLOETJES, H. Enhanced ELAN functionality for sign language corpora. Proceedings of LREC 2008, Sixth International Conference on Language Resources and Evaluation, 2008, 39-43. 
DEUCHAR, M. \& QUAY, S. Language choice in the earliest utterances: A case study with methodological implications. Journal of Child Language 26(2), 1999, 461-475.

DONATI, C. \& BRANCHINI, C. "Challenging linearization: Simultaneous mixing in the production of bimodal bilinguals," in Challenges to linearization, ed. T. Biberauer \& I. Roberts (Berlin: Mouton De Gruyter), 2013, 93-128.

DÖPKE, S. One Parent - One Language: An Interactional Approach. Amsterdam: John Benjamins. 1992.

EMMOREY, K.; BORINSTEIN, H.B.; THOMPSON, R. \& GOLLAN, T.H. Bimodal bilingualism. Bilingualism: Language and Cognition 11(1), 2008, 43-61. EMMOREY, K.; LUK, G.; PYERS, J.E. \& BIALYSTOK, E. The source of enhanced cognitive control in bilinguals: Evidence from bimodal bilinguals. Psychological Science 19(12), 2008, 1201-1206.

FUNG, C. Code-Blending in Early Hong Kong Sign Language: A Case Study. M.A. thesis, The Chinese University of Hong Kong. 2012.

GENESEE, F. Early bilingual development: One language or two? Journal of Child Language 16, 1989, 161-179.

GENESEE, F.; NICOLADIS, E. \& PARADIS, J. Language differentiation in early bilingual development. Journal of Child Language 22, 1995, 611-631.

GENESEE, F. \& NICOLADIS, E. "Bilingual acquisition," in Handbook of language development, eds. E. Hoff \& M. Shatz (Oxford, England: Blackwell), 2007, 324-342. GONZALEZ-VILABAZO, K. \& LÓPEZ, L. Little v and parametric variation. Natural Language and Linguistic Theory 30 (1), 2012, 33-77.

GRIFFITH, P. L. Mode-switching and mode-finding in a hearing child of deaf parents. Sign Language Studies 48, 1985, 195-222.

GROSJEAN, F. Neurolinguist, beware! The bilingual is not two monolinguals in one person. Brain and Language 36, 1989, 3-15.

HALLE, M. \& MARANTZ, A.. "Distributed Morphology and the pieces of inflection," in The view from Building 20: Essays in honor of Sylvain Bromberger, eds. K. Hale \& S. J. Keyser (Cambridge, MA: MIT Press), 1993, 111-176.

KANTO, L.; HUTTUNEN, K. \& LAASKO, M-L. Relationship between the linguistic environments and early bilingual language development of hearing children in Deaf-parented families. Journal of Deaf Studies and Deaf Education 18(2), 2013, 242-260.

KOULIDOBROVA, E. When the Quiet Surfaces: 'Transfer' of Argument Omission in the Speech of ASL-English Bilinguals. PhD. Dissertation, University of Connecticut. 2012. 
KROLL, J.F. \& STEWART, E. Category interference in translation and picture naming: Evidence for asymmetric connections between bilingual memory representations. Journal of Memory and Language 33(2), 1994, 149-174.

KROLL , J.F.; BOBB, S.C. \& WODNIECKA, Z. Language selectivity is the exception, not the rule: Arguments against a fixed locus of language selection in bilingual speech. Bilingualism: Language and Cognition 9(2), 2006, 119-135.

LANZA, E. Language Mixing in Infant Bilingualism. New York: Oxford University Press. 1997.

LILLO-MARTIN, D.; QUADROS, R.M.; KOULIDOBROVA, H. \& CHEN PICHLER, D. "Bimodal bilingual cross-language influence in unexpected domains," in Language acquisition and development: Proceedings of GALA 2009, eds. J. Costa, A. Castro, M. Lobo \& F. Pratas (Newcastle upon Tyne: Cambridge Scholars Press), 2010, 264-275.

LILLO-MARTIN, D.; KOULIDOBROVA, H.; QUADROS, R.M. \& CHEN PICHLER, D. "Bilingual language synthesis: Evidence from WH-questions in bimodal bilinguals," in Proceedings of the $36^{\text {th }}$ Annual Boston University Conference on Language Development, eds. A.K. Biller, E.Y. Chung \& A.E. Kimball (Somerville, MA: Cascadilla Press), 2012, 302-314.

LUCAS, C. \& VALLI, C. Language Contact in the American DeafCommunity. San Diego: Academic Press. 1992.

MACSWAN, J. The architecture of the bilingual language faculty: Evidence from intrasentential code switching. Bilingualism: Language and Cognition 3(1), 2000, 37-54.

MACSWAN, J. Codeswitching and generative grammar. Bilingualism: Language and Cognition 8, 2005, 1-22.

MALLORY, B.L.; ZINGLE, H.W. \& SCHEIN, J.D. Intergenerational communication modes in deaf-parented families. Sign Language Studies 78, 1993, 73- 92.

MYERS-SCOTTON, C. Duelling Languages: Grammatical Structure in Codeswitching. Oxford: Clarendon Press. (1993 [1997 edition with a new Afterword]).

NICOLADIS, E. \& GENESEE, F. A longitudinal study of language differentiation in young bilingual children. Language Learning 46(3), 1996, 439-464.

NICOLADIS, E. \& SECCO, G. The role of a child's productive vocabulary in the language choice of a bilingual family. First Language 20, 2000, 003-028.

OZÇALISKAN, S. \& GOLDIN-MEADOW, S. Gesture is at the cutting edge of early language development. Cognition 96(3), 2005, B101-B113. 
PARADIS, J. Do bilingual two-year-olds have separate phonological systems? International Journal of Bilingualism 5(1), 2001, 19-38.

ARADIS, J. \& NICOLADIS, E. The influence of dominance and sociolinguistic context on bilingual preschoolers' language choice. The International Journal of Bilingual Education and Bilingualism 10, 2007, 277-297.

PETITTO, L.A.; KATERELOS, M.; LEVI, B.; GAUNA, K.; TETRAULT, K. \& FERRARO, V. Bilingual signed and spoken language acquisition from birth: Implications for the mechanisms underlying early bilingual language acquisition. Journal of Child Language 28(2), 2001, 453-496.

PETROJ, V.; GUERRERA, K. \& DAVIDSON, K. ASL dominant code-blending in the whispering of bimodal bilingual children. Proceedings of the $36^{\text {th }}$ Annual Boston University Conference on Language Development. 2014.

PIZER, G. Sign and Speech in Family Interaction: Language Choices of Deaf Parents and their Hearing Children. Ph.D. dissertation, University of Texas, Austin. 2008.

POPLACK, S. Sometimes I'll start a sentence in Spanish y termino en español: Toward a typology of code-switching. Linguistics 18, 1980, 581-618.

PYERS, J. \& EMMOREY, K. The face of bimodal bilingualism: Grammatical markers in American Sign Language are produced when bilinguals speak to English monolinguals. Psychological Science 19, 2008, 531-535.

QUADROS, R.M.; LILLO-MARTIN, D. \& CHEN PICHLER, D. Bi-National Bimodal Bi-Lingual Corpora of Child Language. In Proceedings of the VIIth GSCP (Gruppo di Studi sulla Comunicazione Parlata) International Conference: Speech and Corpora, eds. H. Mello, M. Pettorino \& T. Raso (Firenze: Firenze University Press), 2012, 87-92.

QUADROS, R.M.; LILLO-MARTIN, D. \& CHEN PICHLER, D. Early effects of bilingualism on WH-question structures: Insight from sign-speech bilingualism. In Proceedings of GALA 2011, eds. S. Stavrakaki, M. Lalioti \& P. Konstantinopoulou (Newcastle upon Tyne: Cambridge Scholars Press), 2013, 300-308.

QUADROS, R.M.; LILLO-MARTIN, D. \& CHEN PICHLER, D. Methodological considerations for the development and use of sign language acquisition data. In T. Raso, H. Mello \& M. Pettorino (Eds.), Spoken Corpora and Linguistic Studies. John Benjamins Publishers. (no prelo)

SHOOK, A.; \& MARIAN, V. Bimodal bilinguals co-activate both languages during spoken comprehension. Cognition 124, 2012, 314-324.

UNSWORTH, S. Current issues in multilingual first language acquisition. Annual Review of Applied Linguistics 33, 2013, 21-50.

VAN DEN BOGAERDE, B. Input and Interaction in DeafFamilies. Ph.D. dissertation, University of Amsterdam. Utrecht, the Netherlands: LOT Publications. 2000. 
VAN DEN BOGAERDE, B. \& BAKER, A.E. Code mixing in mother-child interaction in Deaf families. Sign Language and Linguistics 8, 2005, 153-176.

VAN DEN BOGAERDE, B.; \& BAKER, A.E. Bimodal language acquisition in Kodas (kids of deaf adults). In Hearing, Mother-Father Deaf: Hearing People in Deaf Families, eds. M. Bishop \& S.L. Hicks (Washington, DC: Gallaudet University Press), 2009, 99-131.

VOLTERRA, V. \& TAESCHNER, T. The acquisition and development of language by bilingual children. Journal of Child Language 5, 1978, 311-326.

Data de submissão: 07/07/2014. Data de aprovação: 01/09/2014. 